\title{
ENTRE A BELEZA DO MORTO E A CULTURA VIVA: a(s) cultura(s) popular(es) na virada do milênio e seus mediadores simbólicos ${ }^{1}$
}

\author{
Maria Celeste Mira*
}

\begin{abstract}
O objetivo do artigo é contribuir para o debate sobre o tema da "cultura popular", abraçado na universidade por diferentes disciplinas como a Antropologia, a História, a Literatura, a Sociologia e outras. Trata-se de um conceito que, apesar de sua extrema ambiguidade, quando menos se espera, volta a nos interrogar. Considerando o ressurgimento do interesse pelas práticas relacionadas a essa noção, no final do século XX, o texto tenta responder, em que medida elas a transformaram mais uma vez. Partindo do princípio de que o conceito de cultura popular é formulado por intelectuais, como mediadores simbólicos entre as classes populares e outros grupos de interesse, a metodologia adotada foi o estudo dos agentes culturais atualmente envolvidos com a questão, a saber: os próprios folcloristas, as ONGs, gestores culturais do Estado e grupos informais na cidade de São Paulo. Após o exame de algumas práticas e crenças dos novos intelectuais da cultura popular, conclui-se haver mudanças relevantes em relação ao período folclorista, embora vários traços do velho conceito resistam ao tempo e mesmo se fortaleçam com sua associação à causa da "diversidade cultural".
\end{abstract}

PaLAvras-chave: Cultura popular. Tradição. Cultura brasileira. Políticas culturais-intelectuais.

\section{INTRODUÇÃO: a retomada do inte- resse por cultura popular}

Desde os anos 1980 do século XX, é notável um grande reflorescimento das culturas populares e tradicionais em várias partes do mundo. Sem mencionar o aspecto conflituoso do fortalecimento das tradições, que não será tratado aqui, verificou-se o crescimento de festivais, festas, representações históricas, todo tipo de celebração dos costumes do passado para um público de turistas e consumidores ávidos por desfrutar da experiência dessa nova ambientação. Multiplicaram-se filmes, séries, documentários, telenovelas, extensa produção audiovisual destinada a espectadores interessados em se transportar para os tempos de outrora. O tradicional, o popular e o étnico transformaram-se em um novo conjunto de possibilidades estilís-

\footnotetext{
* Pontifície Universidade Católica de São Paulo - PUC/SP. Programa de Estudos Pós-Graduados em Ciências Sociais. Rua Ministro Godói, 969- sala 4E20. Cep: 05014-001. Perdizes - São Paulo- São Paulo. celestemira@gmail.com

${ }^{1} \mathrm{O}$ artigo apresenta as principais conclusões da pesquisa realizada na cidade de São Paulo e alguns municípios do interior do estado, entre 2003 e 2013, cujo texto foi apresentado como exigência parcial para obtenção do título de livre-docente em Antropologia e Sociologia da Cultura na PUC/SP em 2014.
}

ticas absorvidos, antes dos demais, pela música, resultando na chamada world music, no design de moda e de interiores apoiado no artesanato popular, na gastronomia contemporânea inspirada nas culinárias tradicionais, regionais e locais - apenas para citar alguns setores da produção cultural nos quais o fato é mais evidente.

A amplitude e a abrangência da retomada de práticas consideradas como tradições é tal, que se poderia falar de um verdadeiro renascimento. No entanto, as apropriações de caráter francamente mercadológico são apenas uma parte de sua manifestação. No cenário contemporâneo, o sucesso da noção de cultura popular está ligado à sua associação a uma série de debates centrais da "sociedade global" (Ianni, 1992). Embora existam tradições de elite (Mayer, 1987), a noção de cultura popular sempre foi pensada como ligada ao passado e, portanto, como sinônimo de tradição (Ortiz, 1992). Porém, além do grande valor atribuído às tradições na contemporaneidade, a ideia de cultura popular pode evocar, ainda, outros temas em pauta, como: memória, patrimônio, alteridade, etnicidade, comunidade, localidade, identidade e diversidade. Na entrada do terceiro milênio, 
quando passa a ser narrada no plural, como “culturas populares", o conceito desloca-se significativamente de seu sentido folclórico para tornar-se quase sinônimo de "diversidade cultural”. E isso ocorre em um momento em que a crítica ao modelo de desenvolvimento capitalista como fator de destruição do planeta já atingiu o senso comum. Desde 1972, é oficial. A Conferência da ONU sobre o Meio Ambiente em Estocolmo associou a questão da biodiversidade à da diversidade cultural (Mattelart, 2005).

O discurso da diversidade cultural, nas palavras de Armand Mattelart (2005, p. 133), "tende a se tornar uma referência maior na busca de um novo ordenamento do planeta”. A impressão que se tem é a de que o mundo nunca foi tão diverso. Provavelmente, antes o era mais. No entanto, antes das modernas tecnologias de comunicação e de transportes, a diversidade não podia ser percebida. As distâncias físicas as separavam umas das outras. Portanto, a diversidade de que falamos hoje explode na nossa percepção, na possibilidade de entrar em contato com ela e, cada vez mais, experienciá -la. É provável que muito da antiga diversidade cultural tenha se perdido, o que aconteceu, sem dúvida, com a construção dos estados nacionais (Anderson, 1989). Porém, na virada do milênio, quando a "alta modernidade" (Giddens, 1991) acirra as características que lhe são próprias, como o desenraizamento generalizado e a aceleração do tempo, é possível afirmar que novas diversidades culturais estejam surgindo.

Noções como sincretismo, hibridismo ou multiculturalismo, entre outras, surgiram ou ressurgiram para explicar o novo cenário cultui. ral, ao mesmo tempo global e culturalmente he¿ terogêneo. Como demonstrou Michel Nicolau oิ Netto (2014), o conceito de diversidade triunfou $\therefore$ sobre todos os demais, inclusive o de multiculturalismo. O fato é que esses conceitos não são apenas categorias explicativas, mas informam atos de gestão cultural, orientam ações afirmativas por parte dos movimentos organizados, fundamentam as práticas dos agentes culturais em suas disputas. O sucesso dos conceitos aca- dêmicos passa a depender também do diálogo obtido com os movimentos sociais e o Estado. Desde a última década do século XX, dentro e fora da academia, tem-se formado uma nova camada de intelectuais que, vinculados a artistas e grupos considerados tradicionais na esfera da cultura popular, estão reelaborando, mais uma vez, o seu significado. Adentramos, portanto, em um novo momento na história das apropriações das práticas populares e da reformulação do conceito de cultura popular.

Com a centralidade ocupada pela esfera da cultura no cenário contemporâneo, tanto do ponto de vista político quanto do econômico, no contexto global, nacional ou local, na vida pessoal ou coletiva, sob os mais diferentes aspectos (Hall, 1997; Lash; Urry, 1998; Yúdice, 2004; Zukin, 2000), aumentou o número de instituições de caráter público e privado vinculados a ela. Nessa nova e grande esfera da cultura, alargada, dentre outros fatores, pela ampliação da própria noção, tende a se formar, em decorrência, uma nova camada de agentes culturais.

No caso da cultura popular tradicional, os novos agentes estão, antes de tudo, entre os gestores culturais vinculados a órgãos estatais de diferentes níveis hierárquicos, nos quais foram sendo criados secretarias, departamentos ou setores de cultura, acompanhando o crescimento da curva da demanda por esse tipo de ação pública; são também gestores de empresas privadas que investem em culturas tradicionais, com seus programas de fomento, projetos de resgate e geração de renda, cujas campanhas publicitárias milionárias lhes devolvem a imagem da pureza, da limpeza e da ingenuidade associada, no nosso imaginário, à “cultura popular". Um agente que ocupa papel central no novo contexto da cultura popular são as ONGs. Porém esse não é um fenômeno específico. George Yúdice (2004) definiu essa tendência como "ong-ização da cultura". O importante é saber que as ONGs se firmaram como via de ação política no Brasil nos anos 1990, assumindo o lugar ocupado pelos movimentos sociais (Doimo, 1995) e que al- 
guns agentes culturais tornaram-se líderes de movimentos políticos pelas culturas populares em sua nova forma de organização de luta, os fóruns. Há, também, grupos informais, cuja relação com a cultura popular é mais experimental, os quais denominamos de "grupos recriadores”. Do lado oposto a eles, estão os produtores culturais stricto sensu, para os quais a cultura popular tradicional representa apenas interesse econômico. Novos agentes são, ainda, os acadêmicos, professores e pesquisadores universitários para os quais se abriu uma nova problemática, o que lhes permite ministrar cursos, interna e externamente, orientar trabalhos de graduação e pós-graduação, organizar e pautar congressos e assumir cargos públicos.

Tenham ou não consciência do fato, todos eles assumem a função de intelectuais, no sentido gramsciano do termo (Gramsci, 1985). Espalhados na massa, dispersos em seus cargos, postos e funções, posições de poder e visões de mundo, esses intelectuais se tornam, por meio de suas práticas e representações, os novos intérpretes das "tradições populares". Pertencentes, em geral, às classes médias, os novos intelectuais das culturas populares, como preferem chamá-las, tornam-se os novos mediadores simbólicos (Ortiz, 1985) entre as classes populares e o Estado, ou entre elas e o mercado cultural. Esse fato não é novo. A mediação dos intelectuais faz parte da própria história do que entendemos por cultura popular.

O objetivo deste texto é contribuir para o debate sobre o tema da "cultura popular". Partindo do princípio de que o conceito de cultura popular resulta da constante formulação e reformulação de intelectuais, como mediadores simbólicos entre as classes populares e outros grupos de interesse, a metodologia adotada foi o estudo dos agentes culturais envolvidos com sua prática. No entanto, tendo em mente que esse processo - como outros processos socioculturais - acontece num tempo que os historiadores qualificam como de "longa duração", este texto se inicia com a contextualização histórica do debate sobre o tema, cujo peso sobre as ações e concepções contemporâneas é bastante significativo. Prossegue-se, então, com o exame das propostas e realizações dos atores presentes na cena cultural paulistana entre 1988 e 2013, a saber: os próprios folcloristas, as ONGs, os gestores culturais do Estado, os grupos informais, aqui denominados "recriadores", e o autodenominado "Movimento das Culturas Populares". ${ }^{2}$ A análise final leva à confirmação da hipótese inicial de que algumas práticas e crenças dos "novos intelectuais da cultura popular" introduzem mudanças relevantes em relação ao período folclorista, embora vários traços do velho conceito resistam ao tempo e mesmo se fortaleçam com sua associação à causa da "diversidade cultural".

\section{O DEBATE SOBRE A CULTURA PO- PULAR}

O conceito de cultura popular tem sido objeto de intensas disputas, tanto no campo acadêmico como no da produção cultural. Pode-se mesmo dizer que ele é, de fato, uma construção dos próprios agentes envolvidos com o conjunto de práticas reunidas sob este rótulo desde o século XIX, os quais constantemente o reformulam e, ao mesmo tempo, o reiteram. Nesse processo, talvez não exista discordância maior entre os contendores do que a oposição entre cultura popular e cultura de massas. Por esse motivo, atenção especial será dada a esse ponto.

O debate sobre a cultura popular tem uma história. Sua origem remonta à formulação do conceito entre o final do século XVIII

${ }^{2} \mathrm{O}$ estudo das práticas e representações dos agentes envolvidos com “cultura popular” em São Paulo foi feito por meio de um conjunto variado de técnicas de pesquisa ao longo dos dez anos de duração da investigação que gerou a tese de livre-docência da autora - nota 2 deste texto (Mira, 2016), a saber: trabalho de campo, envolvendo observação participante, em festas populares e eventos culturais na capital e em algumas cidades do interior de São Paulo; em torno de 20 entrevistas com depoimentos de agentes culturais, como gestores de cultura, líderes de ONGs e de grupos recriadores, militantes do Movimento das Culturas Populares etc.; consulta a sites desses eventos, órgãos, organizações ou grupos, quando disponíveis. Ao longo do artigo, menciona-se, em cada citação, como o dado foi colhido, remetendo o leitor para o item Referências Bibliográficas. 
e o início do XIX. De acordo com Peter Burke (1989), a ideia de cultura popular começa a se delinear a partir da valorização que os românticos vão fazer da volta à natureza, ao campo, sinônimos da simplicidade e da autenticidade que a nascente civilização moderna começava a conspurcar. Influenciados pelo romantismo, outros intelectuais, sobretudo nos países periféricos da Europa, notadamente na Alemanha, darão acabamento ao conceito de cultura popular. Com a finalidade de se contrapor à cultura das cortes francesas, imitada pelas elites de seu país, um grupo de intelectuais alemães, dentre os quais se destacou Johann Herder, cunha o conceito de cultura popular. Sob esse conceito estavam compreendidos os contos e cantos dos camponeses, suas danças e outras formas de expressão capazes de representar a pureza e a essência da nação.

É o período da identificação entre cultura popular e folclore. Percebendo a urbanização e a industrialização como ameaça ao que passaram a denominar de cultura popular, ou seja, a cultura do mundo tradicional dos camponeses, os folcloristas se apressaram a coletar e classificar suas práticas, obviamente corrigindo os erros gramaticais e tudo o que consideraram vulgar, excessivo ou licencioso, ou seja, impróprio para famílias e crianças, às $\stackrel{q}{q}$ quais eram dirigidas, por exemplo, as coleções de contos dos Irmãos Grimm. Essa construção conservadora do conceito de cultura popular deixará marcas profundas no debate sobre o tema e mesmo na percepção do senso comum sobre a cultura do povo como algo ingênuo, supersticioso e ultrapassado.

Na segunda metade do século XX, os historiadores, sobretudo os medievalistas e aqueles vinculados à história das mentalidades, trazem novos elementos para o debate. Eles redescobrem a Idade Média, antes rotulada como "Idade das Trevas", e, com ela, a cultura do povo, a cultura ordinária, no campo e na cidade. Com forte viés antropológico, os historiadores passam a estudar hábitos e costumes como o amor e o casamento, as festas, as formas literárias, a comicidade etc. a partir de uma nova visão, despida do conservadorismo do século XIX. Seus trabalhos revelam que havia uma rica e diversa produção cultural popular que convergia para a festa. Lembremos, aqui, do importante trabalho de Mikhail Bakhtin (1987) que renovou completamente a compreensão da noção de cultura popular após sua publicação.

Embora divirjam em outros pontos, há certo consenso entre os historiadores europeus sobre o fato de que essa cultura festiva, cuja liberalidade era permitida em ocasióes especiais, a partir do século XVI, começa a ser reprimida por vários setores da sociedade. De acordo com Peter Burke (1989), a igreja católica passa a considerá-la herética (havia, no seu repertório, por exemplo, missas cômicas, paródias de todos os textos canônicos etc.). Com a Reforma Protestante, a cultura da festa passa a ser condenada por ser motivo de ócio, desperdício e licenciosidade. As elites, nobreza e burguesia em ascensão, apanhadas pelo que Elias (1990) denominou "a civilização dos costumes", se afastarão dela por sua vulgaridade e mau gosto. Finalmente, o processo de Esclarecimento levará à condenação dessas práticas por sua irracionalidade. Um novo modo de vida será difundido por meio do ensino público e gratuito, ao longo do século XIX, baseado no espírito científico. Finalmente, uma nova disciplina do trabalho será imposta às classes populares na indústria moderna, eliminando a grande quantidade de festas e feriados, ocasiões em que as formas de expressão dessa cultura popular tinham lugar (Burke, 1989; Thompson, 1998).

Durante o período áureo da cultura popular tradicional, os nobres transitavam entre o universo da cultura das elites e o da cultura popular. Quanto mais voltamos no tempo, mais a cultura popular teria sido a cultura de todos os iletrados, ou seja, do povo, de grande parte da nobreza e do baixo clero. É por essa razão que o historiador Peter Burke (1989) vai dizer que, no século XIX, a cultura popular foi redescoberta. Ou teria sido inventada, interroga-se o autor? Também. Porque, ainda que 
houvesse um conjunto de práticas culturais relacionadas às classes populares, não havia o conceito de cultura popular. Porém a visão de mundo dos intelectuais que fabricaram o conceito fez com que eles elegessem e recortassem, do conjunto das práticas culturais populares, aquelas que receberiam o título de cultura popular. Outras foram excluídas.

Não foi por acaso que o conceito de cultura popular foi inventado justamente no momento em que emergiu a primeira forma de cultura de mercado que se manifestou nos meios impressos. A grande produção e circulação de jornais, revistas, livros e outros tipos de impressos, em um período no qual os países europeus alfabetizavam em massa suas populações, levou os intelectuais a temerem, naquele momento, sobretudo, pela chamada literatura oral. Além da questão da nacionalidade, é no contexto do surgimento da cultura de mercado que se forma essa concepção de cultura popular de traço conservador, marcada pela idealização do povo e pela cristalização de um conceito que pouco tem a ver com a cultura efetivamente vivida pelas classes populares (Ortiz, 1992).

Nesse momento, ocorre a cisão entre duas culturas populares, que passam a ser consideradas antagônicas no debate sobre o tema: a cultura popular de massa (García-Canclini, 1997; Martín-Barbero, 1987; Ortiz, 1988; Ramos, 2004) versus a "autêntica", a "verdadeira" cultura popular. Esse modo de ver a cultura popular é extremamente arraigado no nosso imaginário, de modo que é hegemônico no sentido mais preciso do conceito gramsciano. Ele se torna senso comum, fundindo cultura e ideologia. Essa construção, que identifica o popular ao autêntico, ao "genuíno", ao "essencial”, “de raiz”, não dá sinais de mudança.

O argumento de que a cultura de massa também é cultura popular não se baseia apenas no fato de que ela é consumida pelas classes populares. Em Dos meios às mediações, Jesus Martín-Barbero (1987) apresentou longa pesquisa sobre a gestação da cultura de massas a partir da cultura popular tradicional.
Revelou, por exemplo, como a popularíssima telenovela latino-americana vem da "matriz cultural" do melodrama, forma de teatro popular de rua, cuja origem, por sua vez, remonta à cultura festiva da praça pública. Não foi por acaso que esse teatro de rua era o mesmo que Herder (apud Burke, 1989, p. 49) desclassificava do conceito de cultura popular, ao afirmar que "o povo não é a turba das ruas, que nunca canta nem compõe, mas grita e mutila”. Disso se deduz que parte dos elementos da cultura popular tradicional foi apropriada pela cultura de mercado e parte obteve a chancela dos folcloristas e se tornou cultura popular.

Uma vez que, para esses intelectuais, a autenticidade do popular certamente estava no campo, não se enquadraram na noção de cultura popular as práticas urbanas, supostamente já corrompidas pelas mudanças trazidas pelo mundo moderno. Porém, percebe-se, algo mais os incomodava: os excessos cometidos nos espetáculos populares, como deixa entrever a fala de Herder. Era o excesso de lágrimas do melodrama, o histrionismo do bufão, a licenciosidade dos textos e representações, o comportamento insinuante das atrizes, os erros gramaticais dos impressos (Bollème, 1988). Era como se distinguia o "falso" do "verdadeiro popular".

Desde então, o debate se polarizou. Essa dinâmica de "desautenticação" pelo mercado conhece novo episódio no final do século XIX, início do XX, quando a indústria do entretenimento dá um novo salto com a passagem das antigas feiras de divertimentos para a explosão de estabelecimentos de diversão, como cafés, teatros, cinemas, locais de espetáculos populares como o vaudeville etc. Novamente, a cultura popular urbana será considerada fonte de conspurcação da autenticidade da cultura popular, uma vez que versões reputadas como tradicionais são apropriadas por artistas e produtores culturais e adaptadas para os palcos e o público das cidades. Entre os defensores do folclore como essência da qual deve ser extraída a nacionalidade, por exemplo, Mário de Andrade e Béla Bartók, surge outro termo 
para designar o falso popular: a noção de popularesco. De acordo com Elisabeth Travassos (1997), nesse momento, em várias línguas, surgem palavras com o mesmo significado.

No Brasil, a história do debate sobre cultura popular é muito semelhante. Baseia-se na mesma separação entre cultura de massa e cultura popular, mesmo porque os conceitos foram herdados da tradição europeia. Desde o trabalho incansável de coleta e tentativa de dar cientificidade a nosso folclore, empreendido por Mário de Andrade até o Movimento Folclórico Brasileiro (Vilhena, 1997), criado por Renato Almeida em 1947, a visão de cultura popular permanece ligada ao que está no campo, no passado, ao que não foi maculado pela civilização urbano-industrial.

A saída para esse impasse pode estar na solução apresentada por Roger Chartier e Stuart Hall. Eles sugerem que a cultura popular não seja entendida como um conjunto de práticas ou objetos. Chartier (1995) propõe que pensemos no popular como uma forma de apropriação. O autor se refere à forma como as classes populares se apropriam do que produzem para elas, do que proíbem que elas façam etc. Inspirado na ideia de "invenção do cotidiano" de Michel de Certeau (1994), Chartier pensa na "lógica dos usos" para definir o que é popular. Stuart Hall (2003) parte do mesmo raciocínio, afirmando que o conteúdo não importa, pois pode passar do lado das classes populares para o das elites. Para o autor, o domínio da cultura popular é o de um espaço de lutas, de tensões entre a cultura das elites e a cultura da periferia. No seu entender, a cultura das elites seria aquela valorizada pela escola, a cultura legítima no sentido de Bourdieu (1988). Tradicionalmente, sem dúvida. Mas podemos pensar que novas legitimidades são construídas pela via da cultura de massas, por meio da publicidade, das marcas de luxo, do culto às celebridades às quais as elites aderem, sem dúvida. Isso significa que o repertório da cultura de massas pode ser ora popular, ora de elite. Por isso, não se trata de opor uma cultura à outra, mas de analisar de qual delas as elites retiram sua legitimidade em detrimento da cultura das classes populares. Isso pode acontecer, muitas vezes, com a apropriação de práticas tradicionalmente referidas ao universo da cultura popular tradicional (ou folclórica), quando apresentadas, por exemplo, em exposições elegantes e intelectualizadas das quais, no entanto, as classes populares estão totalmente excluídas.

\section{ENTRE A BELEZA DO MORTO E A CULTURA VIVA: os mediadores da cultura popular}

Michel de Certeau (1995) atribuiu aos estudiosos da cultura popular o gosto pela "beleza do morto”. Para o autor, a cultura popular nasceu não apenas da pena dos intelectuais, mas de atos policiais referentes a apreensões e inquéritos sobre as práticas das classes populares proibidas e perseguidas. Grande parte do que se sabe sobre o assunto na Europa dos séculos XVI a XIX, como informam vários historiadores, tem como fonte arquivos policiais ou judiciais. Para Certeau (1995), a cultura popular foi primeiro censurada para depois ser estudada, teve de deixar de ser perigosa para poder ser nacional, antes foi morta e depois cultuada. Em sua análise, o autor chama a atenção para a permanência desse elemento mórbido constitutivo do conceito de cultura popular nas abordagens não apenas dos folcloristas, mas também dos historiadores. Poderíamos estender essa preocupação para o cenário contemporâneo. No momento em que tanto se proclama a ideia de "cultura viva", é preciso prestar muita atenção à atração exercida pela beleza do morto.

Cultura Viva foi o nome escolhido pelo Ministério da Cultura para batizar um dos mais amplos programas de incentivo direto do Estado a iniciativas culturais que, dificilmente, conseguiriam recursos pela Lei Rouanet de incentivo à cultura. O Programa Cultura Viva, criado em 2005, abriu a possiblidade de múl- 
tiplos locais e atividades culturais, em sentido amplo, conquistarem seu reconhecimento como "pontos de cultura", momento a partir do qual passavam a receber do Estado equipamentos e recursos financeiros. Embora com problemas operacionais, o programa foi muito bem sucedido, tendo sido o seu modelo aplicado, inclusive, em outros países.

Porém Cultura Viva foi mais do que um programa de fomento. Foi a representação em torno da qual todo um conjunto de ações e de agentes ligados à cultura popular tradicional puderam se agregar. Basta lembrar alguns exemplos como: o Prêmio Capoeira Viva, da Fundação Gregório de Matos, a partir de 2006; o Instituto África Viva, inaugurado em São Paulo no mesmo ano; o Museu Vivo do Fandango, mantido pela Associação Cultural Caburé do Rio de Janeiro; o Museu Vivo do Garimpo, criado em Mucugê (BA), em 2006; o Museu Vivo da Memória Candanga, de Brasília etc. Servindo como uma luva para o caso dos museus, os exemplos poderiam se multiplicar. Os termos "vivo", "viva" e "vida" deram nome a instituições, projetos, exposições, apresentações, debates e eventos sem fim.

Na São Paulo da virada do milênio, como nos quatro cantos do país, a palavra de ordem também era "cultura viva". O folclore e os museus eram considerados coisas mortas por um grupo de novos agentes culturais voltados para a pesquisa e a recriação de cultura popular na cidade. Um deles era Paulo Dias, criador e diretor da Associação Cultural Cachuera!, uma ONG destinada a pesquisa, produção e divulgação da cultura popular tradicional. Ao abrir ao público os arquivos da associação no evento sugestivamente denominado Acervo com Vida, ele afirmou:

Existem algumas denominações para a cultura que o povo produz. Uma delas é folclore e, mais recentemente, cultura popular. Eu devo confessar a vocês que eu não gosto de nenhuma das duas. Porque as duas são restritivas, elas colocam a cultura do povo, como uma coisa separada, seja com o termo folcló- rico, seja com o termo cultura popular. [...] O Antonio Nóbrega tem um espetáculo que chama Cultura popular não é folclore que é legal porque folclore é um termo que realmente é o lugar do povo na cultura brasileira, o lugarzinho. Então chega lá o mês de agosto [...] todo mundo fala: 'Ah! O dia do folclore' que inventaram uma palavra folk-lore em inglês [...] não é o nosso caso aqui. ${ }^{3}$ (grifo nosso).

A fala de Paulo Dias não expressa apenas uma convicção pessoal. Há uma recusa generalizada do termo folclore por parte dos novos agentes da cultura popular tradicional, na cidade São Paulo. Porém não se trata - como se poderia imaginar - de um percurso que leva, da beleza do morto, à cultura viva. Parece haver por parte dos atuais atores sociais muito mais uma tensão entre velhos e novos sentidos e usos do conceito de cultura popular. $\mathrm{Ou}$, como diriam certos historiadores, pode-se notar um conjunto de permanências e rupturas com o passado do conceito no momento de sua criação, o século XIX. Em outras palavras, havia e há certo preconceito com o trabalho dos folcloristas ao se atribuir apenas a eles o culto da beleza do morto, da mesma maneira que o rótulo "cultura viva” não os impede de cair em velhas armadilhas do conceito de cultura popular.

A partir dessa perspectiva, é possível identificar quatro tipos de mediadores atuantes na metrópole paulistana desde a última década do século XX. Seus discursos, projetos e realizações permitem delinear as concepções de cultura popular que os sustentam: a visão folclórica; a estética; a lúdica-vivencial; e a politizada. ${ }^{4}$ Destacados do espaço social, tinham as principais características de um campo, no sentido de Bourdieu (1988): um grupo de agentes sociais, dispostos em posições hierarquizadas, a partir das quais discutem e disputam questões específicas, no caso, a cultura popular.

${ }^{3}$ Paulo Dias palestras na abertura do Acervo Cachuera, São Paulo, Espaço Cachuera em 22 e 29/08/2002, transcrição da autora.

${ }^{4}$ Não será tratado aqui o caso dos produtores culturais stricto sensu, aqueles que se aproximaram do setor apenas com interesses econômicos. 


\section{VELHOS E NOVOS ATORES DA (S) CULTURA (S) POPULAR (ES) NA METRÓPOLE PAULISTANA}

Com a retomada do interesse pelas culturas populares, os folcloristas saem do ostracismo. Sua moeda de troca volta a ter valor. Em São Paulo, o Movimento Folclórico Brasileiro (Vilhena, 1997) deixara uma comissão estadual bem estruturada e um grande líder, Rossini Tavares de Lima, discípulo e ex-aluno de Mario de Andrade no Conservatório Dramático e Musical de São Paulo. Rossini também teve seus discípulos, dentre eles, Antonio Teixeira de Macedo. Herdeiro do folclorismo de Rossini, Macedo mantém, junto ao governo de São Paulo, o modo tradicional de se relacionar com o Estado, ou seja, pela via da ocupação de espaço em um órgão do poder a fim de obter recursos para a viabilização de suas atividades. Outra via são os assentos no Conselho Estadual de Cultura, do qual faz parte a Comissão Paulista de Folclore, cujo cargo, exercido por Rossini durante muitos anos, também foi herdado por Macedo.

Porém Toninho Macedo, como é conhecido por todos no meio, foi muito além de seu mentor. Criou e dirige o evento da Secretaria de Estado da Cultura, Revelando São Paulo, que ocorre na capital paulista desde 1997, ${ }^{5}$

๑ Anunciado como o evento que "traz o interior ㄱ. para a capital”, o Revelando São Paulo pode ser ळ descrito como uma gigantesca e modernizada xima ao centro da cidade, dezenas de grupos populares tradicionais, visivelmente reconstituídos há pouco tempo, como, por exemplo, Folias de Reis e do Divino, quadrilhas, grupos de fandango, de catira, de cururu, violeiros, sanfoneiros, congadas, moçambiques, além do que seu criador, Toninho Macedo, denominou "manifestações cosmopolitas", a fim de incorporar a presença dos grupos não tradicionais, como os jovens paulistanos praticantes de jongo, maracatu, tambor de crioula e outros batuques. Simultaneamente, espalhavam-se pelo parque outras atrações, a exemplo da adoração da imagem de Nossa Senhora Aparecida, vinda do Santuário, a Festa de Cosme e Damião, os desfiles de bonecões e cabeções, a movimentação de carros de boi e tropas de mulas, o Rancho Tropeiro e as Cavalhadas de São Luís de Paraitinga. A maior concentração de público, porém, acontecia no considerável conjunto de barracas que oferecia, de um lado, a culinária, com pratos regionais, café caipira, doces caseiros e, de outro, o artesanato considerado de tradição. A concepção do Revelando São Paulo é a de mostrar tudo ao mesmo tempo e no mesmo lugar. De acordo com dados anunciados em 2009, haviam participado do festival 180 munícipios e um público aproximado de um milhão de pessoas. Em 2005, o Revelando São Paulo foi proclamado oficialmente o maior evento de cultura do governo estadual, superando o Festival de Inverno de Campos do Jordão.

A posição oposta à de Toninho Macedo pode ser encontrada em várias realizações da Associação Cultural Cachuera!, cujas atividades de pesquisa sobre cultura popular tradicional tiveram início em 1988 e, desde 1997, constitui uma ONG. O Revelando São Paulo é percebido por esses novos agentes da cultura popular como exemplo da descontextualização promovida pelas festas de folclore, que reúnem as mais diferentes expressões na mesma situação. A realização mais representativa do novo ponto de vista é a promoção, pela Associação Cultural Cachuera!, da Festa do Divino das Caixeiras da Casa Fanti Ashanti. Na tentativa de se 
aproximar o máximo possível do seu contexto original, a Associação a escolheu como a única festa de caráter popular e tradicional a ser realizada por ano. A cerimônia acontece no Espaço Cachuera! e nas ruas do bairro por onde passam os cortejos. Sua duração é de nove dias, tendo início com o levantamento do mastro e a abertura da tribuna e encerrando-se com os seus respectivos tombamento e fechamento. Duas caixeiras são trazidas da Casa Fanti-Ashanti de São Luís do Maranhão e duas vivem em São Paulo. Assim, são reunidas a mãe, duas filhas e uma neta que, no decorrer da semana, além dos rituais da festa, oferecem oficinas às mulheres de São Paulo que queiram aprender a tocar caixa e participar da festa. Dindinha, a mais velha, é responsável pelo caráter sagrado da festa e, de acordo com o diretor da associação, a cada ano, introduz novos aspectos rituais, conforme cresce sua confiança nos participantes paulistanos. Desse modo, foram incorporados à festa, dentre outros elementos, o Império, o imperador menino, lugar ocupado por uma criança de São Paulo, os dons do Divino, personificados também por crianças, os bolos de que elas gostam e, finalmente, na festa de 2005, "apareceu um Erê que ficou e queria comer bolo". ${ }^{6}$

Além do grande evento no Parque, o Revelando chegou a promover três cortejos pela metrópole, um deles vindo do Largo do Paissandu, no centro da cidade. A concepção de Toninho Macedo foi herdada dos folcloristas. Renato Almeida acreditava na estratégia do "rumor" (Vilhena, 1997, p. 197). Era o que o Movimento Folclórico fazia em seus congressos: grandes festivais de folclore com cortejos ou desfiles dos grupos folclóricos pelas ruas da cidade para chamar a atenção das autoridades para sua importância e consequente necessidade de subvenção. A posição da Associação Cachuera!, por sua vez, foi sustentada, no seu início, por financiamento próprio e, após sua legitimação no campo, pela sua conversão em ONG e capacitação para captação de incenti-

${ }^{6}$ Paulo Dias, depoimento, entrevista concedida à autora, São Paulo, Espaço Cachuera, em 24/05/2005. vos à cultura, tanto públicos quanto privados. Por esse motivo, pode-se dizer que a Associação Cachuera! representaria, no campo da cultura popular, o que seria, no campo da arte, a ideia da "arte pela arte" (Bourdieu,1996), ou seja, a cultura popular pela cultura popular.

Um dos focos do trabalho da Associação Cachuera! é a valorização estética da cultura popular tradicional. E essa é uma diferença importante em relação ao passado folclorista e nacionalista, quando se pensava que a cultura do povo era importante como raiz, como essência, a ser processada, porém, pelos artistas cultos para tornar-se cultura nacional. Sendo erudito em música, pois estudou piano na França, tendo sido professor do Coral da USP, Paulo Dias tem legitimidade para afirmar a equivalência estética entre a cultura erudita e a cultura popular tradicional. Basta consulta-la para verificar que, da programação da Associação Cachuera!, pode constar, em uma determinada data, a apresentação de um quarteto de Bach e, em outra, a de um batuque de umbigada.

Entre esses dois extremos, os grupos aos quais denominamos "recriadores" assumem posições intermediárias. Surgidos no mesmo período, de meados dos anos 1990 à metade dos 2000, trata-se de coletivos interessados em cultura popular tradicional que não podem mais ser classificados nem como tradicionais ou folclóricos, nem como para-folclóricos. De modo diferente dos parafolclóricos, os grupos recriadores não têm como objetivo apenas reproduzir as danças folclóricas. São formados por grupos de amigos, em geral estudantes do ensino médio ou universitário, em particular da área de Ciências Humanas, na sua maioria brancos e de classe média. Obviamente, o fato de ser essa a sua composição não quer dizer que eles sejam os produtores originais dessas práticas. Ao contrário, a novidade que trazem para a Sociologia da Cultura diz respeito à emergência, na metrópole, de um conjunto de práticas culturais tradicionais sem relação com o fenômeno da migração. ${ }^{7}$ De início, seu objetivo era vivenciar, ${ }^{7}$ Normalmente é visto como exceção o Grupo Cupuaçu, 
por meio do encontro com as chamadas "comunidades", ou seja, os grupos de artistas populares por eles (re) descobertos, a tradição e o espírito comunitário. Ao longo dos anos 2000, passaram a fazer apresentações e a performatizar a tradição. Alguns grupos alcançaram um nível de profissionalização precária, outros continuaram a encarar a cultura popular tradicional como vivência lúdica ou comunitária.

Como os demais agentes recém-chegados ao campo, os membros dos grupos recriadores adotam as novas ideias sobre cultura popular: "não é folclore", "é cultura viva", "tem todo um contexto ritual, religioso, sagrado que é preciso respeitar". Os jovens integrantes dos grupos recriadores se interessam pelas tradições populares justamente por essas características que buscam vivenciar. Mas não é nada desprezível a importância de seu potencial lúdico em termos de música, dança e percussão, tanto para sua própria diversão, quanto para sua transformação em espetáculo (Mira, 2009). O apego às tradições por eles demonstrado não os impede de fazerem apresentações pagas, darem aulas e cursos, enfim, comercializar a "cultura popular". O pequeno nicho de mercado aberto pela retomada do interesse por essas práticas, na cidade de São Paulo, tornou-se, combinado com outras atividades, uma de suas formas de sobrevivência. A outra, que foi se tornando, ao longo 공 do novo século, cada vez mais promissora, foi 凶ં a de obter financiamento por meio das novas políticas públicas para as "culturas populares". i Se, até a década de 1990, o interesse por cultura popular era muito pequeno, não havia, como constatou Marcelo, ${ }^{8}$ legislação alguma ¿. que dotasse recursos para essas práticas, a não \& ser as migalhas recolhidas pelas comissões iे estaduais de folclore. Alguns integrantes de grupos recriadores da cidade, dentre eles Marcelo Manzatti, formado em Ciências Sociais pela USP, ex-aluno de Paulo Dias e seu braço

ligado a migrantes maranhenses. Porém sua criação se deu por iniciativa dos alunos do curso de danças brasileiras ministrado por seu líder, Tião Carvalho (MIRA, 2016).

${ }^{8}$ Marcelo Manzatti, entrevista concedida à autora, São Paulo, escritório da autora, em 01/10/2010. direito na criação da Associação Cachuera!, se politizaram. Começaram a participar de conferências municipais de cultura na gestão do PT e decidiram criar sua própria frente de luta, gerando o que viria a ser o autodenominado Movimento das Culturas Populares.

No ano de 2002, inspirado no "Movimento Arte contra a Barbárie”, que havia conquistado subsídios para o teatro paulistano, Marcelo Manzatti reuniu-se a outros ativistas para dar início ao Fórum Permanente para as Culturas Populares de São Paulo. O objetivo era agregar todos os grupos e instituições interessados em cultura popular tradicional para obter investimentos públicos para o setor. Os fóruns, de acordo com Maria da Glória Gohn (2010), são a principal forma de organização dos novos movimentos sociais. Uma de suas características, segundo a autora, seria a de promover ações de maior alcance, por exemplo, encontros nacionais em larga escala, gerando grandes diagnósticos dos problemas sociais, bem como definindo metas e objetivos estratégicos para solucioná-los (Gohn, 2010).

No caso do emergente Movimento das Culturas Populares, a proposta do Fórum Permanente de São Paulo para o Ministério da Cultura foi a de realização de um seminário nacional sobre o tema das políticas culturais para as culturas populares. Isso se tornou possível porque Gilberto Gil, tendo assumido o Ministério da Cultura do governo do presidente Luís Inácio Lula da Silva, no início de 2003, já começara a implantar diretrizes para a cultura no Brasil, em consonância com os intuitos do Movimento. Basta lembrar que, em seu discurso de posse, o Ministro Gil, por assim dizer, oficializou a recusa do termo folclore:

Do mesmo modo, ninguém aqui vai me ouvir pronunciar a palavra 'folclore'. Os vínculos entre o conceito erudito de 'folclore' e a discriminação cultural são mais do que estreitos. São íntimos. 'Folclore' é tudo aquilo que - não se enquadrando, por sua antiguidade, no panorama da cultura de massa - é produzido por gente inculta, por 'primitivos contemporâneos', como uma espécie de enclave sim- 
bólico, historicamente atrasado, no mundo atual. Os ensinamentos de Lina Bo Bardi me preveniram definitivamente contra essa armadilha. Não existe 'folclore' - o que existe é cultura (Gil, 2003).

Ao mesmo tempo em que aproximava o Ministério da Cultura do Movimento das Culturas Populares, a visão ampliada de Gilberto Gil fazia coro com o discurso da Unesco, que se apoiava, cada vez mais, do conceito antropológico de cultura (Pitombo, 2011).

Essa convergência de percepções e interesses permitiu a realização do I Seminário Nacional de Políticas Públicas para as Culturas Populares, em Brasília, no ano de 2005, fato inédito na história do país. O seminário foi organizado pela Secretaria da Identidade e Diversidade Cultural, o Fórum de São Paulo e o Fórum Permanente para as Culturas Populares e o Patrimônio Imaterial do Rio de Janeiro, criado em 2003 e vinculado ao Centro Nacional de Folclore e Cultura Popular. No ano seguinte, foi realizado o segundo e último seminário. Mudanças no interior do MinC levaram à sua interrupção. No entanto, considerando que, sob o rótulo de folclore, não era possível senão pedir o amparo do Estado para uma produção cultural que tendia ao desaparecimento, houve uma significativa mudança.

Reunindo todas as expressões populares e tradicionais em uma nova denominação e politizando-a junto ao Estado, aos mediadores e aos próprios praticantes, o Movimento conseguiu constituir as "culturas populares" como um setor das políticas públicas do Estado, outro fato inédito. Logo após o I Seminário, o MinC lançou, por meio da extinta Secretaria da Identidade e Diversidade Cultural, o Prêmio Culturas Populares, o qual disponibilizou quase nove milhões de reais para financiar projetos na área, o suficiente para contemplar muitos grupos (MinC, 2010). Com a criação do Conselho Nacional de Políticas Públicas pelo governo federal, em 2005, a atuação do Movimento direcionou-se para a conquista de um lugar para as culturas populares nesse conselho, ao lado de setores já consagrados, como a
Música, a Dança, o Teatro, a Literatura, as Artes Cênicas, o Audiovisual etc. Valendo-se da Rede das Culturas Populares e Tradicionais organização que reunia os 27 fóruns estaduais, então já existentes, criada em 2006 -, obteve êxito. Em 2009, o Movimento conseguiu implantar dois novos colegiados no Conselho Nacional de Políticas Culturais, em funcionamento desde 2007: o de Culturas Populares e, em seguida, o de Culturas Indígenas. Mais tarde, viriam as Culturas Afro-Brasileiras, também integradas ao atual Fórum para as Culturas Populares e Tradicionais. Em 2010, as "culturas populares” foram institucionalizadas como setor das políticas públicas de cultura, ocupando lugar de destaque no Plano Nacional de Cultura, aprovado nos últimos dias do governo do presidente Lula.

\section{CULTURAS POPULARES, IDENTI- DADES E DIVERSIDADE CULTURAL}

O novo ordenamento mundial, como o nomeou Armand Mattelart, (2005) funda-se na consideração da diversidade cultural como um valor em si mesma. Em um mundo majoritariamente dominado pela crença no achatamento das diferenças pessoais e coletivas pela globalização, o diferente é bem vindo em qualquer situação e ganha operacionalidade por meio do conceito de diversidade cultural. Nesse contexto, a cultura popular passa a ser vista na sua pluralidade, o que, em geral, significa evidenciar suas diversas expressões, sotaques, regiões etc. Por um lado, isso enseja a construção de novas identidades que estavam aplainadas pelo conceito de nação, nacionalidade ou identidade nacional. O samba é, provavelmente, o melhor exemplo. Os batuques de ex-escravos deram origem a vários tipos de samba. Porém, no momento de construção da identidade nacional que é única porque representa a unificação da cultura e do poder sobre um mesmo território, o samba do Rio de Janeiro, capital do país, foi escolhido para ser seu 
símbolo. Os outros sambas ficaram fora dessa construção e dos holofotes da nascente cultura de massas no Brasil, que levou o Samba com S maiúsculo para o rádio e, posteriormente, para a televisão. Esses meios confirmaram o samba carioca, ao lado do futebol, como símbolo de brasilidade, no mundo todo.

O outro lado da supervalorização da brasilidade era, obviamente, a anulação da possibilidade concreta de construção de outras identidades. O samba, cuja matriz cultural é negra, teve de embranquecer. O samba deixou de ser negro para ser brasileiro. Com o processo mundial de reconstrução das identidades afrodescendentes, a reafricanização da música negra no Brasil, o movimento negro brasileiro, o surgimento de uma série de entidades ligadas à cultura e arte negra, o sentimento de pertencimento cresceu e a afirmação da identidade negra passou a prevalecer em alguns gêneros musicais como o axé, o funk, o hip hop e outros. O samba, além de resgatar sua negritude, se multiplicou em diversos outros, obscurecidos por várias décadas: o samba de roda, o jongo, o batuque de umbigada, o tambor de crioula, o samba rural paulista, entre outros. Não é coincidência que essas expressões, caídas no esquecimento, sejam exatamente aquelas pelas quais se interessam os atuais recriadores da cultura popular.

A ênfase no caráter afrodescendente da cultura brasileira representa uma ruptura significativa com o passado. Não parece casual que a Associação Cultural Cachuera! tenha tido início justamente no ano de 1988, a partir de uma pesquisa de seu diretor sobre o candomblé. $\mathrm{O}$ ano marcou a comemoração do centenário da abolição e o surgimento de novas instituições voltadas para a afirmação e a divulgação da cultura e da arte negras. O candomblé bem como a cultura e a arte negras não foram a porta de entrada para essa nova visão da cultura popular apenas para a Associação Cachuera!, mas para outros grupos recriadores no mesmo período. Vários líderes e participantes de grupos recriadores também entraram em contato com o repertório da cultura popular tradicional por sua proximidade com o universo do que coloquialmente se chama de "dança-afro" e outras práticas relacionadas à cultura e à arte negras na metrópole paulistana. Embora os terreiros de candomblé, xangô, tambor de mina, jurema, umbanda ou outras denominações sempre estivessem ligados à maioria das práticas culturais tradicionais populares, não o eram de forma assumida. Ao contrário, muitas vezes, as atividades profanas serviam de fachada para ocultar a devoção proibida por lei e perseguida pela polícia. Essa é a diferença no cenário contemporâneo. $\mathrm{O}$ aspecto afrodescendente é realçado com orgulho. Pode-se afirmar, com segurança, que a cultura brasileira, na virada do milênio, é mais negra do que nunca.

No cenário cultural contemporâneo, uma prática vinculada à cultura popular tradicional, como a congada, por exemplo, pode se apresentar como cultura brasileira, cultura negra, cultura popular, ou ainda como cultura afro-brasileira, entre outras possíveis construções. A porosidade das fronteiras identitárias, pessoais ou coletivas, permite e, ao mesmo tempo, exige uma pluralidade de construções. Num contexto social "pós-identitário", os atores sociais aprenderam a "jogar o jogo das tradições" (Hall, 1997), a teatralizar suas memórias, a representar suas identidades de acordo com suas crenças e interesses, sejam eles econômicos ou simbólicos (Bourdieu, 1997). Entre eles, estão os recursos financeiros disponibilizados pelo Estado, em particular pelo governo federal, a partir da gestão do presidente Lula. Na primeira metade dos anos 2000, havia a possibilidade de os grupos populares se candidatarem a diferentes modalidades de incentivos do Programa Cultura Viva, ao Prêmio Culturas Populares, aos da Fundação Palmares, no caso dessa última destinados apenas às culturas de matriz africana. Podiam ainda obter financiamentos ao se identificarem como "populações tradicionais", "quilombolas", "griôs", "povos de terreiro" etc. ${ }^{9}$ Para tanto, bastava realçar as características simbólicas que os aproximavam mais de um ou de outro refe-

${ }^{9}$ Essas eram algumas denominações observáveis nos debates da Rede das Culturas Populares no período de 2006 a 2013. 
rente (Poutignat; Streiff-Fernat, 1998).

Por outro lado, é importante notar que a ideia de identidade afro-brasileira constitui uma nova síntese (Ortiz, 1980) na história das versões da cultura brasileira. Em primeiro lugar, ela incorpora e, portanto, reconhece a importância da matriz africana e passa a legitimá-la nos círculos onde for empregada. Em segundo lugar, a identidade afro-brasileira constitui uma nova síntese em que a matriz africana é enfatizada, mas a brasilidade é mantida. Esse fato é importante porque não se perde a nacionalidade como referente para a construção identitária.

$\mathrm{O}$ vínculo com a nacionalidade, no caso, com a cultura brasileira, é outro traço muito resistente do conceito de cultura popular. Mesmo sendo escrita no plural, como "culturas populares”, a noção não se desprende da sua relação com o nacional. Porém a maneira como a nação é construída, na "alta modernidade” (Giddens,1991), muda de perspectiva. Se, no período áureo do nacionalismo dos Estados-Nação, no caso brasileiro, as décadas de 1930 e 1940 do século XX, falava-se em unidade nacional, na fusão das raças e culturas no mesmo território, agora se exalta a diversidade étnica e cultural que constitui a nação. A construção da nacionalidade tende a enfatizar não a sua unidade, mas a "diversidade cultural" contida no seu interior. E as "culturas populares" têm sido consideradas imprescindíveis para a composição do grande mosaico étnico-cultural brasileiro. Permanecendo nacional, a cultura popular, mesmo no plural, continua a ser questão de Estado.

Nesse contexto, há um deslocamento de todas as construções simbólicas e todos os conceitos para o plural. Se a cultura popular muda para culturas populares, também a cultura brasileira se desloca para culturas brasileiras. Há vários exemplos dessa pluralização da identidade brasileira. Em primeiro lugar, a valorização das culturas populares também está ligada ao fortalecimento das localidades e regionalidades. Na primeira década do terceiro milênio, falou-se bastante em mineiridade, pernambucanidade, etc. Cada um dos cantos e recantos do país foi objeto de viagens, reportagens, publicações, projetos de todo tipo. Um deles, na área do audiovisual, já teve cinco edições bem sucedidas. Seu nome representa bem o momento: Revelando os Brasis (Revelando os Brasis, 2016). Outro exemplo é o Pavilhão das Culturas Brasileiras, construído em São Paulo, em 2010, para abrigar o que havia restado do Museu do Folclore de São Paulo. Nesse caso, a pluralidade da noção permitiu abrigar, além desse acervo, fruto do trabalho de Rossini Tavares de Lima, a arte indígena, a arte vernacular, a cultura da periferia etc. Abriu espaço também para estetizações das culturas populares e tradicionais por artistas e estilistas ligados a esse universo. De qualquer modo, observa-se que cresce, entre os agentes culturais, a percepção de que a cultura brasileira é plural.

\section{CONCLUSÃO: o inclassificável popular}

O atual interesse pelas culturas populares não representa apenas um apelo nostálgico ao passado. Sua retomada se insere, como vimos, no quadro mundial de revival das tradições, com vistas à preservação da diversidade cultural, por sua vez, considerada necessária à manutenção da biodiversidade. Enquanto os folcloristas preservavam o passado para que ele não desaparecesse, os atuais mediadores das culturas populares entendem que sua proteção pode representar o futuro do planeta e da humanidade. A força da ideia de diversidade entra no terceiro milênio como uma crença salvacionista.

Apesar de olharem para o futuro e de recusarem peremptoriamente o termo folclore, os novos intelectuais das culturas populares, no entanto, estão mais presos ao passado do que imaginam. Embora concordem que a tradição é algo mutável, que se transforma com o tempo, continuam a buscar as expressões populares na sua forma mais autêntica, tal como no tempo dos folcloristas. Esse atrelamento tem relação com o próprio conceito de cultura popular e toda a "estrutura de sentimentos” (Williams, 1979) que a 
insere no quadro da consciência nacional.

Como vimos, a nacionalidade da cultura popular foi proclamada pelos intelectuais no momento em que o folclore estava sendo cada vez mais abandonado pelas classes populares. Devido à modernização capitalista, os servos estavam sendo expulsos das terras que cultivavam, a urbanização era intensa e, nas cidades, as classes populares estavam adotando uma variedade de outros hábitos culturais, sobretudo os oferecidos pela nascente indústria do entretenimento. Como vimos, o conceito de cultura popular já nasceu distante da realidade cultural das classes populares.

Pode-se visualizar a cultura das classes populares como cultura das classes trabalhadoras, em alguns períodos históricos, em determinadas cidades. Mais recentemente, podem-se analisar as práticas populares como uma série de subculturas urbanas, cada vez mais variadas, diversas, dispersas e complexas, em meio à massa supostamente homogênea. Porém o conceito predominante entre os atuais líderes de grupos ou associações de cultura popular ainda está longe de contemplar todas essas variantes. Por maiores que sejam as divergências entre os atores sociais do campo da cultura popular em São Paulo, todos traçam uma linha divisória entre o repertório com o qual trabalham, que seria a "verdadeira" cultura popular, e o que faz a "mídia" e (ou) o mercado. A Associação Cultu¿ ral Cachuera!, por exemplo, aceita a existência de um popular tradicional e de um popular urbano. Mas, ao examinar-se um projeto como o Cachuera! de Música, realizado em 2005, percebe-se que o máximo que ele incorpora ao status de cultura popular urbana é o samba das escolas de samba. Por sua vez, na Rede das Culturas Populares e Tradicionais, uma grande frente política, cuja tendência é incluir todos que se autoproclamem populares, a única manifestação de cultura popular, urbana e moderna, cujas mensagens circulam é o hip hop. Como se sabe, rap, sua linguagem musical, se contrapõe à mídia e ao mercado de música gravada. Mas as concessões não vão muito além. Os recortes e as escolhas que se materializam nos projetos e políticas culturais continuam sustentando a barreira que separa a cultura popular da cultura de massas, mantendo o conceito bem defendido das expressões sem qualidade estética, "fabricadas pela mídia”, coincidentemente, também, as mais desconcertantes, perigosas e de difícil classificação como o axé, o funk, o pagode, o brega, o arrocha etc. etc.

Afastado do mercado, o conceito de culturas populares permanece fortemente politizado. Reformulando o discurso da brasilidade, deslocando seu acento da identidade nacional para a diversidade cultural, o Movimento das Culturas Populares obtém o mesmo efeito. Se a diversidade das culturas populares constitui a riqueza da nação, o Estado nacional deve protegê-las e promovê-las. Talvez essa compensação seja absolutamente necessária em termos econômico-financeiros. As culturas populares e tradicionais, assim como a arte erudita, não conseguem se sustentar pela via do mercado. Elas dependem do Estado (Miceli, 1984), enquanto as práticas populares urbanas, mais próximas do cotidiano das classes populares, podem ser facilmente mercantilizadas.

Em síntese, no contexto cultural contemporâneo, pontos recorrentes do debate sobre cultura(s) popular(es) se recolocam, em particular, a oposição entre cultura popular e cultura de massas. Desta vez, a grande ameaça, no imaginário dos artistas e dos intérpretes das culturas populares, é a globalização. Mais do que a cultura de massas, a indústria cultural ou a mídia, a globalização é percebida como a invasão da nação por uma cultura americana ou americanizada de forma tão avassaladora, que destruirá as diversas culturas populares e regionais.

O fato é que, a cada momento em que se apresenta uma ameaça ao conceito de cultura popular, refaz-se a aliança entre intelectuais, acadêmicos ou não, produtores, agentes e gestores culturais para salvar a(s) cultura(s) popular(es). A cada nova onda de "resgate", no entanto, eles se refugiam em torno de um con- 
ceito de cultura popular cada vez mais restrito, quando comparado à heterogênea produção cultural das classes populares.

Recebido para publicação em 21 de abril de 2016 Aceito em 05 de setembro de 2016

\section{REFERÊNCIAS}

ANDERSON, B. Nação e consciência nacional. São Paulo: Ática, 1989.

BAKHTIN, M. A cultura popular na idade média e no renascimento: o contexto de François Rabelais. São Paulo: Hucitec, 1987.

BOLLÈME, G. O povo por escrito. São Paulo: Martins Fontes, 1988.

BOURDIEU, P. La distinción criterios y bases sociales del gusto. Madri: Taurus, 1988.

. As regras da arte: gênese e estrutura do campo literário. São Paulo: Cia. das Letras, 1996.

É possível um ato desinteressado? In: . Razões

práticas sobre a teoria da ação. Campinas: Papirus, 1997.

BURKE, P. Cultura popular na idade moderna: Europa 1500-1800. São Paulo: Companhia das Letras, 1989.

CERTEAU, M. de. A invenção do cotidiano. Artes de fazer. Petrópolis: Vozes, 1994.

A beleza do morto. In: Campinas: Papirus, 1995. . A cultura no plural.

CHARTIER, R. "Cultura popular": revisitando um conceito historiográfico. Estudos históricos, Rio de Janeiro, v. 8, n. 16, 1995.

DOIMO, A. M. A vez e a voz do popular: movimentos sociais e participação política no Brasil pós-70. Rio de Janeiro: Relume Dumará: Anpocs, 1995.

ELIAS, N. O processo civilizador: uma história dos costumes. Rio de Janeiro: Zahar, 1990. 2v.

GARCÍA CANCLINI, N. Culturas híbridas: estratégias para entrar e sair da modernidade. São Paulo: Edusp, 1997.

GIDDENS, A. As consequências da modernidade. São Paulo: Editora da Unesp, 1991.

GIL, G. Discurso na solenidade de transmissão do cargo. 2003. Disponível em: <http://www.gilbertogil.com.br/sec_texto. php?id=3\&page $=2 \& i d \_t y p e=3>$. Acesso em: 17 nov. 2007 .

GOHN, M. da G. (Org.). Movimentos sociais no início do século XXI: antigos e novos atores sociais. Petrópolis: Vozes, 2010.

GRAMSCI, A. Contribuições para uma história dos intelectuais. In: . Os intelectuais e a organização do cultura. 5. ed. Rio de Janeiro: Civilização Brasileira, 1985.

HALL, S. A centralidade da cultura: notas sobre as revoluções culturais do nosso tempo. Educação $\mathcal{E}$ Realidade, Porto Alegre, v. 22, n. 2, p. 15-46, jul./dez. 1997.

. A identidade cultural na pós-modernidade. Rio de Janeiro: DP\&A, 1997.

Notas sobre a desconstrução do popular. In: SOVIK, L. (Org.). Da diáspora: identidades e mediações culturais. Belo Horizonte: UFMG, 2003.

IANNI, O. A sociedade global. Rio de Janeiro: Civilização Brasileira, 1992.
LASH, S.; URRY, J. Economias de signos y espacio: sobre el capitalismo de la posorganización. Buenos Aires: Amorrortu, 1998.

MARTÍN-BARBERO, J. De los medios a las mediaciones: cultura, comunicación y hegemonia. Cidade do México: Gustavo Gili, 1987.

MATTELART, A. Diversidade cultural e mundialização. São Paulo: Parábola, 2005.

MAYER, A. J. A força da tradição: a persistência do Antigo Regime, 1848-1914. São Paulo: Companhia das Letras, 1987.

MICELI, S. (Org.). Estado e cultura no Brasil. São Paulo: Difel, 1984.

MINISTÉRIO DA CULTURA (MINC). Balanço do Programa identidade e diversidade cultural: Brasil plural: editais públicos 2005 a 2010. 2010. Disponível em: < http://www. cultura.gov.br/site/wp-content/uploads/2011/01/balancoeditais-2005-2010.pdf. >. Acesso em: 16 fev. 2011.

MIRA, M. C. Sociabilidade juvenil e práticas culturais tradicionais na cidade de São Paulo. Sociedade e Estado, Brasília, v. 24, n. 2, p. 563-597, maio/ago. 2009.

Entre a beleza do morto e a cultura viva: a(s) cultura(s) popular(es) na cidade de São Paulo e seus mediadores simbólicos. São Paulo: Intermeios: Fapesp, 2016. No prelo.

NICOLAU NETTO, M. O discurso da diversidade e a world music. São Paulo: Annablume: Fapesp, 2014.

ORTIZ, R. Do sincretismo à síntese. In: consciência fragmentada: ensaios de cultura popular religião. Rio de Janeiro: Paz e terra, 1980.

Cultura brasileira e identidade nacional. São Paulo: Brasiliense, 1985.

A moderna tradição brasileira: cultura brasileira e indústria cultural. São Paulo: Brasiliense, 1988.

Cultura popular: românticos e folcloristas. São Paulo: Olho D’Água, 1992.

PITOMBO, M. A diferença como bem universal: a noção de diversidade cultural. In: ALVES, Elder P. M. (Org.). Políticas culturais para as culturas populares no Brasil contemporâneo. Maceió: Edufal, 2011.

POUTIGNAT, P.; STREIFF-FENART, J. Teorias da etnicidade. São Paulo: Editora da Unesp, 1998.

RAMOS, J. M. O. Cinema, televisão, publicidade. 2. ed. São Paulo: Annablume, 2004.

REVELANDO os Brasis. 2016. Disponível em:

$<$ http://www.revelandoosbrasis.com.br/blog/?page $\mathrm{id}=2 \geq$. Acesso em: 10 abr. 2016 .

THOMPSON, E. P. Tempo, disciplina de trabalho e capitalismo industrial. In: . Costumes em comum: estudos sobre a cultura popular tradicional. São Paulo: Companhia das Letras, 1998.

TRAVASSOS, E. Os mandarins milagrosos. Rio de Janeiro: Funarte: Jorge Zahar editor, 1997.

VILHENA, L. R. Projeto e missão: o movimento folclórico brasileiro (1947-1964). Rio de Janeiro: FGV: Funarte, 1997. WILLIAMS, R. Marxismo e literatura. Rio de Janeiro: Jorge Zahar Editores, 1979.

YÚDICE, G. A conveniência da cultura. Belo Horizonte: UFMG, 2004.

ZUKIN, S. The cultures of cities. Massachusetts: Blackwell Publishers Ltd., 2000. 


\section{BETWEEN THE BEAUTY OF THE DEAD AND THE LIVING CULTURE: the popular culture(s) in the turn of the millennium and its symbolic mediators}

\author{
Maria Celeste Mira
}

The objective of this article is to contribute with the debate about the subject of "popular culture", studied in the Academia by different disciplines such as Anthropology, History, Literature, Sociology, among others. It is a concept that, besides its extreme ambiguity, when least expected makes us question ourselves again. Considering the resurgence of the interest in practices related to this concept by the end of the 20th century, this text aims to answer in which measure this concept was once again transformed. Starting at the principle that the concept of popular culture is formulated by intellectuals, the methodology used was the study of cultural agents involved with this question which include folklorists, NGOs, State cultural managers and informal groups of the city of São Paulo. After the examination of some practices and believes of the new intellectuals of the popular culture, it is concluded that relevant changes have occurred since the folklorist period, although some traces of the old concept resist the passing of time and get stronger with the association with "cultural diversity".

Keywords: Popular culture. Tradition. Brazilian culture. Cultural politics. Intellectuals.

\author{
ENTRE LA BEAUTÉ DU MORT ET LA CULTURE \\ VIVANTE: la(les) culture(s) populaire(s) au \\ passage du millénaire et ses (leurs) médiateurs \\ symboliques
}

Maria Celeste Mira

L'objectif de cet article est d'apporter une contribution au débat concernant le thème de la “culture populaire”, thème adopté à l'université par différentes disciplines telles que l'anthropologie, l'histoire, la littérature, la sociologie et d'autres encore. Il s'agit d'un concept qui, malgré son énorme ambiguïté, nous remet en question au moment où on s'y attend le moins. Compte tenu de la résurgence d'un intérêt pour les pratiques liées à cette notion à la fin du XXe siècle, le texte essaie de dire dans quelle mesure elles l'ont à nouveau transformée. En partant du principe selon lequel le concept de culture populaire est formulé par des intellectuels jouant le rôle de médiateurs symboliques entre les classes populaires et les autres groupes d'intérêt, la méthodologie adoptée fut d'étudier les agents culturels actuellement concernés par cette question, à savoir: les folkloristes eux-mêmes, les ONG's, les gestionnaires culturels de l'état et les groupes informels de Sao Paulo. Suite à l'analyse de certaines pratiques et croyances des nouveaux intellectuels de la culture populaire, on en conclut qu'il y a eu des changements importants par rapport à la période folkloriste, même si plusieurs caractéristiques de l'ancien concept résistent au temps, ou encore se fortifient par leur association à la cause de la "diversité culturelle".

Mots-CLÉS: Culture populaire. Tradition. Culture brésilienne. Politiques culturelles-intellectuelles. 